\section{FRI0042 BAFF-R EXPRESSION IN NAÏVE CD5+IGM+ B CELLS IN RHEUMATOID ARTHRITIS PATIENTS REPOPULATING AFTER RITUXIMAB}

E. Becerra ${ }^{1,2}$, I. de la Torre ${ }^{2}$, M.J. Leandro ${ }^{2}$, G. Cambridge ${ }^{2} .{ }^{1}$ Rheumatology, Hospital universitario de Torrevieja, Alicante, Spain; ${ }^{2}$ Rheumatology, University College London, London, United Kingdom

Background: Serum levels of $B$ cell activating factor (BAFF) rise following Rituximab (RTX) therapy in patients with Rheumatoid arthritis (RA). CD5+lgM+B cells are present within transitional and naïve $B$ cell subsets and their increased production or accumulation is associated with some autoimmune diseases. Previous studies have shown that BAFF does not enhance their survival compared with CD5- naïve B cells, suggesting that signalling pathways are important in promoting their survival.

Objectives: To determine serum BAFF levels and BAFF-receptor (BAFF-R) expression in $\mathrm{CD} 5+\mathrm{lgM}+\mathrm{B}$ cells in healthy controls $(\mathrm{HC}), \mathrm{RTX}$-naïve RA patients (pre-RTX), and relapsing at different time points after peripheral $B$ cell repopulation post-RTX treatment, divided into 2 groups: early relapsers (0-3 months post-B cell return) and later relapsers ( $>4$ months post-B cell return).

Methods: Immunophenotyping of peripheral blood mononuclear cells was used to determine \%CD5+lgM+B cells and BAFF-R $\%$ and expression, mean fluorescence intensity (MFI)) in $5 \mathrm{HC}, 13$ pre-RTX and 12 post-RTX RA patients. Results were analyzed with respect to timing of relapse after peripheral $\mathrm{B}$ cell return ( $>5 \mathrm{~B}$ cells $/ \mu \mathrm{L}$ ) and serum BAFF levels.

Results: $\% \mathrm{CD} 5+\lg \mathrm{M}+\mathrm{B}$ cells, but not absolute numbers, were significantly higher in post-RTX early relapsers compared to $H C(p<0.01)$, pre-RTX patients $(p<0.001)$ and post-RTX later relapsers $(p<0.01)$. There was a strong inverse correlation between $\% C D 5+\operatorname{lgM}+B$ cells and time after $B$ cell return $\left(r^{2}=0.88\right.$, $\mathrm{p}<0.0001)$. BAFF-R+ expression was significantly lower in both post-RTX groups compared to $\mathrm{HC}$ and pre-RTX patients; early relapsers showed the lowest \% and MFI BAFF-R+ expression, compared with later relapsers $(p<0.01)$. BAFF-R+ expression increased with time after $B$ cell return, both $\%\left(r^{2}=0.47, p<0.002\right)$ and MFI $\left(r^{2}=0.76, p<0.0004\right)$. BAFF levels were significantly higher in both post-RTX groups compared to HC and pre-RTX patients, with the highest BAFF levels in early relapsers $(p<0.05$ compared to later relapsers). There was a significant inverse correlation between BAFF levels and $\%\left(r^{2}=0.51, p<0.01\right)$ and MFI $\left(r^{2}=0.4, p<0.05\right)$ BAFF-R+ expression.

Conclusions: Early relapsers show increased \%CD5+lgM+ naïve B cells, and decreased BAFF-R expression, similar to ontogeny and what is seen in cord blood $B$ cells. Whether the increased numbers of $\mathrm{CD} 5+$ naïve cells were contributing to relapse was not determined but they have the capacity to rapidly mature into autoantibody producing plasma cells, independent of the BAFF/BAFFR system. BAFF- $R$ expression was found to increase with time after $B$ cell return, again mirroring ontogeny with a later relapse showing more normalized BAFF/BAFF-R levels, suggesting their mechanism of relapse may follow a more conventional $\mathrm{B}$ cell differentiation pathway.

Disclosure of Interest: None declared

DOI: 10.1136/annrheumdis-2017-eular.6604

\section{FRI0043 PEPTIDES HIGHLY SPECIFIC TO THE VARIABLE REGION OF TNF-ALFA-SPECIFIC REFERENCES LICENSED (RL) MONOCLONAL ANTIBODIES (MAB), AS POTENTIAL TOOL TO EFFECTIVELY ASSESS SIMILARITY BETWEEN BIOSIMILARS AND THE CORRESPONDIG RL MAB}

E. Favoino, C. Ionescu, F. Perosa. Department of Biomedical Sciences and Human Oncology, Systemic Rheumatic and Autoimmune Disease Unit, University of Bari Medical School, Bari, Italy

Background: Monoclonal antibodies (mAb) have greatly facilitated the development of highly specific immunotherapy, with a significant improvement of clinical outcome in certain rheumatologic diseases. However, the approaching of many references licensed $\mathrm{mAb}$ (RLM) to the end of their licensing period, have stimulated a tremendous interest in the synthesis of a new generation of low-cost $m A b$ referred to as biosimilars (BS) $m A b$ (BSM), because of their similarity to the RLM. An essential requirement imposed by Regulatory Agencies for a mAb to be considered $B S$ is that its variable region (VR) primary sequence must be highly similar to that of RLM. However, epitope recognition and affinity of a mAb very much depends on its VR conformational structure, which may differ even between two mAb bearing highly similar (but not identical) VR. The availability of reagents highly specific to the RLM VR may offer an unique opportunity to define whether a mAb can or cannot be considered BS to a given RLM.

Objectives: To isolate and characterize phage clone-expressing peptide (pc) which are highly specific for the VR of two anti-TNF- $\alpha$ RLP namely mAb Infliximab (Inf) and Golimumab (Gol).
Methods: Cross-inhibition ELISA on recombinant TNF- $\alpha$ (rTNF- $\alpha$ ) was performed to define the spatial relationship among the epitopes detected by $m A b$. mAbspecific phage clones expressing peptide $(\mathrm{pc})$ were obtained by the panning of a phage peptide display library with TNF-a specific mAb. Characterization of pc-specificity and of the spatial relationship between pc- and the TNF-a-binding site on the variable region of $\mathrm{mAb}$ was assessed by binding and inhibition assay. Results: mAb Inf and Gol specifically and dose-dependently cross-inhibited each to the other in the binding to rTNF-a, indicating the recognition by these $2 \mathrm{mAb}$ of the same or two distinct spatially related epitopes on TNF-a. The panning of $\mathrm{mAb}$ Inf and Gol with a phage peptide display library resulted in the isolation of one Inf-specific pc (pclnf) and three Gol-specific pc (pcGol1 to 3). Binding assay showed that pclnf and the three pcGol specifically reacted with the corresponding $\mathrm{mAb}$. Furthermore, pclnf and pcGol3 specifically and dose-dependently inhibited the binding of the corresponding $m A b$ to $r T N F-\alpha$, suggesting the recognition by the $\mathrm{pc}$ of the corresponding $\mathrm{mAb}$ antigen-combining site. Finally, pclnf and all three pcGol did not react with two additional TNF-a antagonists, suggesting that they are highly specific for mAb Inf and Gol respectively.

Conclusions: The highly specificity of the pc described indicates that they can be eventually employed to predict similarity between a newly synthesized BSM and the claimed RLM, based on the BSM reactivity (or the lack of reactivity) with RLM-specific pc.

Disclosure of Interest: None declared

DOI: 10.1136/annrheumdis-2017-eular.6358

\section{FRI0044 NON-STEROIDAL ANTI-INFLAMMATORY DRUGS ARE MORE BENEFICIAL THAN ANTI-TNF $\alpha$ DRUGS ON THE RADIOGRAPHIC DAMAGE IN ARTHRITIS: A STUDY IN ADJUVANT INDUCED ARTHRITIS}

F. Verhoeven ${ }^{1}$, C. Prati ${ }^{2}$, P. Totoson ${ }^{3}$, R. Bordy ${ }^{3}$, D. Wendling ${ }^{1}$

C. Demougeot ${ }^{3} .{ }^{1}$ Rhumatologie; ${ }^{2} \mathrm{CHRU}$ de Besançon; ${ }^{3}$ Ea 4267 "Pepite", université de Bourgogne Franche Comté, Besançon, France

Background: The management of the chronic inflammatory rheumatisms has dramatically evolved in the last decade with a concept of "treat to target". The theory of a window of opportunity with more beneficial effects of an early intensive treatment is supported by several evidences. The positive impact of an early treatment with a TNF $\alpha$ blocker is expected but the place and the interest of non-steroidal anti-inflammatory treatments (NSAIDs) and glucocorticoids is not clear.

Objectives: The aim of this study was to evaluate the radiological outcomes after an early treatment during 21 days by Etanercept, or Naproxene, or Celecoxib, or Prednisone, or Diclofenac or Methotrexate in adjuvant induced arthritis in rats.

Methods: Adjuvant-induced arthritis (AIA) was induced in 6 weeks old male Lewis rats by injection of Mycobacterium butyricum in adjuvant at the basis of the tail. At the onset of arthritis, rats were daily treated with Naproxene $(10 \mathrm{mg} / \mathrm{kg} / \mathrm{d}$ i.p), or Diclofenac (5mg/kg i.p twice a day), or Celecoxib (3 mg/kg/d i.p) or Prednisone (10 mg/kg/d i.p), or Etanercept (10 mg/kg/3 days, s.c.), or Methotrexate $(1 \mathrm{mg} / \mathrm{kg} / 3$ days, s.c.), or saline solution (Vehicle), for 21 days. Arthritic score was daily monitored. At the end of treatment, paws' radiological exam was performed with a BMA High Resolution Digital X Ray $(40 \mathrm{mV}, 10 \mathrm{~mA})$. A score of 0 to 20 was determined for each paw using a grading scale modified from Ackerman et al (1979).
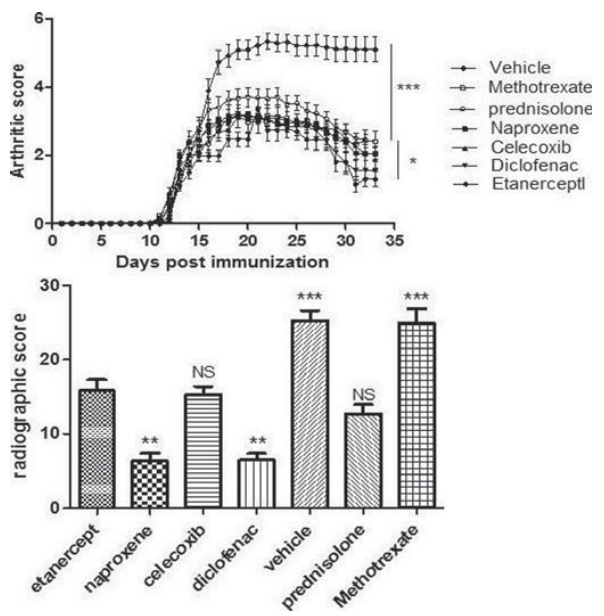

\begin{tabular}{|c|c|c|c|c|}
\hline & $\% \mathrm{CD} 5+\lg \mathrm{M}+$ (median;range) & $\%$ BAFF-R+ve & BAFF-R+ve (MFI) & BAFF levels ( $\mathrm{ng} / \mathrm{ml}$ ) (median;range) \\
\hline $\mathrm{HC}$ & $18.5(9.1-26.8)$ & $98.7(97.9-99.5)$ & $62.5(50.5-82.4)$ & $1.1(0.9-1.2)$ \\
\hline Pre-RTX & $5.4(1.9-21.4)$ & $97.3(85.8-100)$ & $58(34.2-139)$ & $1.4(0.9-1.7)$ \\
\hline Post-RTX early relapse & $44.4(39.6-55.8)$ **\#\#\#\$ & $60.6(12.9-71.2)^{\star \star \# \# \# \$ \$ ~}$ & $15.6(11.8-17.5)^{\star \star \# \# \# \$ \$}$ & 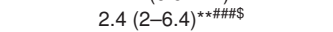 \\
\hline Post-RTX late relapse & $12.7(2.3-27.9)^{\$ \$}$ & $93.1(81.5-97.9)^{\star \star \$ \$}$ & $30.2(19.9-36)^{\star \star \# \# \$ \$ ~}$ & $1.7(1.3-2.4)^{\star \star \# \$}$ \\
\hline
\end{tabular}

${ }^{*} \mathrm{p}<0.05 ;{ }^{* *} \mathrm{p}<0.01 ;{ }^{* \star *} \mathrm{p}<0.001$ compared with NC; $\mathrm{\#}<0.05 ;{ }^{\# \#} \mathrm{p}<0.01 ;{ }^{\# \# \#} \mathrm{p}<0.001$ compared with pre-RTX; ${ }^{\$} \mathrm{p}<0.05 ;{ }^{\$ \$} \mathrm{p}<0.01 ;{ }^{\$ \$ \$} \mathrm{p}<0.001$ for comparisons between post-RTX groups. 